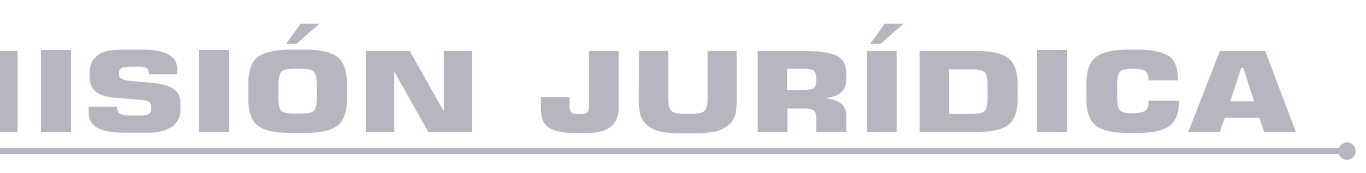

\title{
La formación profesional del abogado y la retórica
}

The regime of public cemeteries: after the dichotomy between

the public and private sectors

Autores: Enrique Farfán Mejía, Antonio Muñozcano Eternod,

Luis Alfonso Perdomo Zambrano

DOl: https://doi.org/10.25058/1794600X.1046

\footnotetext{
Ś MISIÓN JURÍDICA A
} 


\title{
LA FORMACIÓN PROFESIONAL DEL ABOGADO Y LA RETÓRICA*
}

\author{
The professional formation of the lawyer and the retoric
}

A formação profissional do advogado e da retórica

\author{
Enrique Farfán Mejía ${ }^{a}$ \\ efarme@hotmail.com \\ Antonio Muñozcano Eternod ${ }^{b}$ \\ antonio.munoz@tsjcdmx.gob.mx \\ Luis Alfonso Perdomo Zambrano ${ }^{c}$ \\ cines100@hotmail.com \\ Fecha de recepción: 31 de mayo de 2019 \\ Fecha de revisión: 17de junio de 2019 \\ Fecha de aceptación: 25 de junio de 2019
}

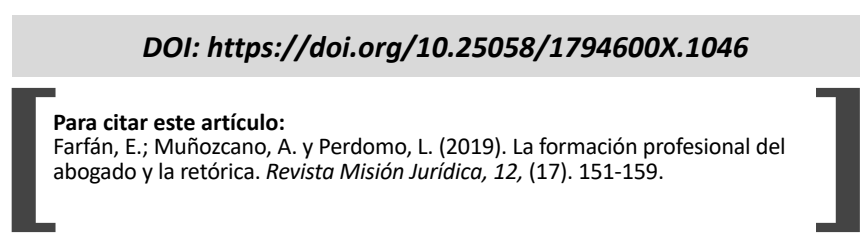

\section{RESUMEN}

El objetivo de este trabajo es examinar las posibilidades que brinda la retórica como recurso pedagógico para desarrollar habilidades lingüísticas necesarias para el eficiente desempeño de los jueces y abogados en los juicios orales, de manera que esta permita el cambio en la práctica. El argumento central es que la retórica es el lenguaje profesional del abogado y que apropiarse de un nuevo lenguaje, durante la formación, significa un cambio cultural.

Para demostrar lo anterior, desde Wittgenstein (1953), se analiza el papel del lenguaje en la formación profesional y se propone el concepto de "lenguaje profesional". Posteriormente se vindica la retórica, señalando el papel que jugaron diversos pensadores en desacreditarla, como fue el caso de Platón (Lara, 2008).

\footnotetext{
* Artículo de reflexión el cual presenta un análisis histórico y crítico respecto a cómo la retórica ha sido una parte central en formación profesional del abogado. A su vez se examinan las posibilidades pedagógicas que brinda la retórica para desarrollar habilidades lingüísticas. Universidad Pedagógica Nacional Unidad 096 CDMX Norte en colaboración con el Tribunal Superior de Justicia de la Ciudad de México.

a. Licenciado y Maestro en Psicología por la UNAM, Diplomado en Política y Retórica por la UNAM, Especialista en Argumentación Jurídica por la Universidad Complutense de Madrid y Doctor en Educación por la Universidad Autónoma de Sinaloa. Profesor investigador en la UPN y asesor en el Tribunal Superior de Justicia de la CDMX. Profesor investigador en la UPN, de donde además es Director de la Unidad 096, y asesor psicopedagógico en el Tribunal Superior de Justicia de la Ciudad de México, para la implementación de los juicios orales en materia familiar, civil y penal. Es miembro del Sistema Nacional de Investigadores como Investigador Nivel I. Institución de adscripción: Universidad Pedagógica Nacional Unidad 096 CDMX Norte.
}

b. Licenciado en Derecho por la UNAM, estudios de especialización en Derecho constitucional y Derecho comercial en la Universidad de Illinois, Estados Unidos de Norteamérica. Maestro en Derecho civil y familiar por la Universidad de Barcelona, España. Doctor en Derecho por la Universidad Tepantlato. En el Tribunal Superior de Justicia de la CDMX es Magistrado en materia familiar. Institución de Adscripción: Tribunal Superior de Justicia de la CDMX. Magistrado de la Cuarta Sala Familiary Magistrado de la Sala Constitucional del Tribunal Superior de Justicia del Distrito Federal. Coordinador de la Implementación de los Juicios Orales en Materia Familiar de la misma institución.

c. Licenciado en Educación con especialidad en Matemáticas por la Escuela Normal Superior de México. Maestro en construcción de habilidades del pensamiento por la Universidad Pedagógica Nacional Unidad CDMX 096 Norte. Catedrático de nivel secundaria y educación media superior. Institución de adscripción: Universidad Pedagógica Nacional Unidad CDMX 096 Norte. 
Al final se hace un recuento histórico de la formación profesional del abogado para mostrar que la retórica formaba parte de esta y se hacen sugerencias pedagógicas sustentadas en la experiencia vivida formando en retórica jurisdiccional y judicial en el Tribunal Superior de Justicia de la Ciudad de México (TSJCDMX).

\section{PALABRAS CLAVE}

Formación profesional; derecho; retórica; lenguaje; pedagogía; habilidades lingüísticas.

\section{ABSTRACT}

The aim of this paper is to examine the possibilities offered by rhetoric as a pedagogical resource to develop necessary language skills for judges and lawyers, for them to have an efficient performance in an oral judgement in a way that allows for a change in this practice.

A central argument is that rhetoric is the judge's professional language and, appropriating a new language during training means a cultural change.

To demonstrate the above, since Wittgenstein (1953), the role of language is analyzed in professional training and concept of "professional language" is proposed. Subsequently rhetoric is vindicated, pointing out the role various thinkers played in discrediting it, as in the case of Plato (Lara, 2008).

At the end a historical recount of lawyers' professional training is made to show that rhetoric was part of it and pedagogical suggestions are made supported by personal experience on training jurisdictional and judicial rhetoric at the Superior Court of Justice in Mexico City (TSJCDMX).

\section{KEYWORD}

Professional formation, legal, rhetoric, language, pedagogy and linguistic skills.

\section{RESUMO}

0 objetivo deste trabalho é examinar as possibilidades de aprendizagem da retórica como recurso pedagógico para aprendizagens de habilidades lingüísticas necessárias para o desempenho eficiente juízes e advogados nos processos orais, de maneira que este permita a mudança na prática. 0 argumento central é que a retórica é a linguagem profissional do advogado e a abordagem de uma nova linguagem, durante a formação, significa uma troca cultural.

Para demonstrar o anterior, desde Wittgenstein (1953), é analisado o papel da linguagem na formação profissional e propõe-se o conceito de "linguagem profissional". Mais tarde, a retórica foi vindicada, apontando o papel desempenhado por vários pensadores em descreditar-la, como foi o caso com Platão (Lara, 2008).

No final, é feita uma conta histórica da formação profissional do advogado para demonstrar que a retórica fazia parte dela e sugestões pedagógicas são feitas com base na experiência vivida formando na retórica judicial e judicial no tribunal Superior de Justiça da cidade do México (TSJCDMX).

\section{PALAVRAS-CHAVE}

Formação profissional; direito; retórica; idioma; pedagogia; competências linguísticas.

\section{INTRODUCCIÓN}

Este artículo aborda el polémico tema de la retórica por medio de su reivindicación en la práctica jurídica; reconociéndola como lenguaje profesional de los abogados que surgió con la formalización de esta antigua práctica originada en Sicilia y sistematizada por Tisias y Corax (Gómez, 2007) para su enseñanza.

En la actualidad la formación para abogado en México y Latinoamérica no considera a la retórica como elemento central en el desarrollo de habilidades lingüísticas, volcándose eminentemente hacia el aprendizaje formal del discurso escrito, lo que muchas veces impide el acto "persuasivo" que busca el abogado frente al juez.

Sin embargo, recientemente apareció un factor que está presionando para el cambio en la práctica: se busca promover el tránsito de juicios eminentemente escritos a eminentemente orales. Lamentablemente, a pesar de la enorme cantidad de recursos que se invierten en este cambio, los resultados no son los mejores (Ríos, 2013; Rivera, 2018). Es por eso que la pregunta fundamental que guio esta comunicación fue ¿Cuáles son 
las posibilidades que brinda la retórica como recurso pedagógico para desarrollar habilidades lingüísticas necesarias para el eficiente desempeño de los jueces y abogados en juicios orales? Nuestra respuesta es que la retórica puede jugar un papel fundamental para formar mejores jueces $y$ abogados para la justicia oral. Nuestro argumento central es que la retórica es el lenguaje profesional del abogado y que, al apropiarse de la retórica durante la formación en el Derecho, se aprende un nuevo lenguaje y este aprendizaje lingüístico significa un cambio cultural. Es así que el objetivo de esta comunicación es examinar las posibilidades que brinda la retórica como recurso pedagógico para desarrollar habilidades lingüísticas necesarias para el eficiente desempeño de los jueces y abogados en los juicios orales.

Para alcanzar este objetivo, en esta comunicación se realiza un análisis acerca del papel del lenguaje en la formación profesional y se propone el concepto de "lenguaje profesional" (Wittgenstein, 1953). Consecutivamente, se muestra la vinculación que hay entre la retórica y el derecho, señalando la importancia que tuvieron diversos autores en la desacreditación de la retórica, así como en su consecuente tergiversación. Finalmente, se hace un recuento histórico de la formación profesional del abogado para mostrar que la retórica formaba parte de esta y se hacen sugerencias pedagógicas sustentadas en la experiencia vivida formando en retórica jurisdiccional y judicial en el Tribunal Superior de Justicia de la Ciudad de México.

\section{La formación profesional y el lenguaje}

Desde la filosofía de Wittgenstein (1953), la formación profesional consiste en aprender un juego del lenguaje. Es decir, el novel profesionista aprende un lenguaje, una forma de pensar el mundo y de actuar en él. Es así que uno de los aspectos en los cuales puede constatarse de manera evidente el proceso paulatino de la formación profesional es en el cambio en el lenguaje del profesionista en formación. Su lenguaje, al hablar acerca de los temas de la profesión se volverá cada vez más técnico y su uso será cada vez más restringido a los otros miembros de su profesión. Así mismo, el profesionista en formación profesional, durante las prácticas y el servicio social hasta llegar al ejercicio independiente cuando tenga la licenciatura, se caracterizará por su expresión técnica. Aún con los contratantes o clientes tenderá a emplear esa forma del lenguaje que reserva para sus colegas. Esta visión de la profesión desde la pragmática del lenguaje es una postura coincidente con la de Hortal (2002) quien al caracterizar a las profesiones señala, como uno de sus rasgos, que estas poseen un "lenguaje esotérico", así como una "larga preparación previa para ejercerla", siendo que el aprendizaje y dominio de este lenguaje esotérico es en parte resultado de esta larga preparación previa. De manera que aprender ese lenguaje de su profesión significa apropiarse de la cultura que identifica a su gremio.

La noción de juego de lenguaje de Wittgenstein (1953) también puede ser útil para comprender el proceso del cambio en la práctica. Las profesiones son actividades vivas sometidas al cambio (Schon, 1998). Los avances científicos, tecnológicos, la guerra, los cambios sociales, la política, la economía, son algunos de los factores extrínsecos que pueden presionar a las profesiones para modificar sus prácticas. También al interior de las profesiones existen factores que promuevan el cambio, como los cambios generacionales, las nuevas técnicas o la aparición de nuevas teorías.

En la profesión de abogado en México y Latinoamérica, recientemente apareció un factor que está presionando para el cambio en la práctica: se busca promover el cambio en la práctica para ir de juicios eminentemente escritos a eminentemente orales. Lamentablemente, a pesar de la enorme cantidad de recursos que se invierten en este cambio, los resultados no son los mejores (Ríos, 2013; Rivera, 2018). Una de las formas en las que se expresa esta dificultad para el cambio reside precisamente en las deficiencias lingüísticas que se muestran en los actores de los juicios orales. Las resistencias y problemas para el cambio en los jueces y litigantes van desde las actitudes desfavorables ante los juicios orales hasta la simulación del cambio donde la oralidad se pervierte en lectura de los textos previamente escritos. Este problema se advierte también en las fallidas muestras de oralidad llenas de titubeos, problemas de dicción, énfasis, etc. (Cáceres, 2016).

Consideramos que estos problemas, aunque son multifactoriales, descansan, sobre todo, en la ausencia de una visión sobre la formación profesional donde se valore el papel que juega el lenguaje, como lo expusimos en los párrafos 
iniciales. Esto deriva en la imposibilidad de advertir la necesidad de una pedagogía de la formación inicial y continua del abogado que promueva el surgimiento de las habilidades lingüísticas necesarias para modificar el lenguaje de la profesión. Es decir, advertimos que se sigue privilegiando, tanto en la Universidad como en las escuelas de los poderes judiciales y en los cursos de actualización, métodos didácticos sustentados en prácticas lingüísticas escritas de las cuales, por alguna razón que no alcanzamos a comprender, se espera que se aprendan prácticas lingüísticas orales ¡Se requiere emplear una pedagogía del derecho que desarrolle de manera sistemática las prácticas lingüísticas orales requeridas para los nuevos juicios oralesi

No estamos diciendo algo que no se esté atendiendo por lo menos incipientemente. La pedagogía de la oralidad descansa en los llamados "simulacros" y en los "casos", así como en la permanencia de formatos didácticos tradicionales como la "clase magistral" (Palma y Elgueta, 2018). Estos dos recursos didácticos son mejoras para promover las habilidades lingüísticas orales, pero no son suficientes. En otras comunicaciones examinamos sus debilidades didácticas y el corto alcance que permiten para sustentar un cambio cultural en la práctica profesional para implementar la justicia oral (Farfán y Molina, 2016).

Otra vía para el cambio hacia la oralidad que se ha explorado es la argumentación (Jiménez, 2013). Con ahínco los abogados en formación y los que ya ejercen se dedican al estudio de las teorías clásicas y modernas de la argumentación. Toulmin, Perelman, Atienza, son algunos de los autores que se revisan. Pero, lamentablemente, las nuevas teorías no son suficientes para promover el cambio en la práctica profesional, aunque son necesarias. Son necesarias porque nutren de técnica y explicación al razonamiento legal, pero no son suficientes porque de su estudio no se genera necesariamente el nuevo desempeño esperado. Sobre todo, cuando este estudio adolece de ejercicios orales donde se practique lo aprendido. El campo de la argumentación, a la vez, abre el camino para otra posibilidad que surge en el horizonte profesional del abogado para impulsar mejoras en el desempeño profesional en los juicios orales y es el camino de la retórica. La demanda social de tener sistemas de justicia eficientes, honestos, transparentes sigue presente $\mathrm{y}$ no puede contentarse con reducidas mejoras en el desempeño de los abogados involucrados en la justicia oral. En este contexto es que algunos investigadores y juristas en México, generaron programas de formación en la práctica que han tenido éxito para preparar para los juicios orales (Muñozcano y Rivera, 2017). En sus comunicaciones reseñan un lento y largo proceso de experiencias centradas en la formación en la práctica que los ha llevado a advertir en la retórica diversos elementos propicios para promover la transformación en la práctica de la profesión.

\subsection{La retórica y el derecho}

La retórica tiene una mala imagen. La retórica es una expresión usada para demeritar la expresión de una persona. Es retórica, se dice, el habla o la escritura vacía, sin sustento, llena de florituras. La retórica es, afirman, falsedad. ¿Cómo entonces pensar en que de la retórica pueda surgir un cambio en la práctica de los abogados? Debemos responder que esto es posible porque estamos ante una tergiversación histórica de la retórica (Adrián, 2008). Para explicarlo haremos una revisión histórica del origen de la retórica. En esta revisión para vindicar la retórica, además, advertiremos la gran cercanía que esta tiene con la práctica del Derecho.

Alrededor del Siglo V antes de Cristo, la recién conquistada democracia llevó a los habitantes de lo que ahora es Sicilia a solucionar algunos problemas de disputas por tierras a través de la palabra y no de la fuerza ni de las armas. Todos los habitantes de esa cultura se dieron un trato igualitario ante la ley y así procedieron para encontrar una solución a sus problemas a través de la palabra.

Esa manera novedosa de solucionar los problemas fue teorizada por dos personajes: Córax y Tisias (Gómez, 2007). Lo que las personas de esa comunidad hacían de manera empírica ellos lo sistematizaron y al hacerlo lo pudieron enseñar. Al enseñar esas habilidades, conocimientos y actitudes fue que surgió la retórica y dio con ello inicio, al mismo tiempo, la formación profesional para la abogacía. Surgió la técnica de la persuasión. Los rétores empezaron a educar a los jóvenes para que, posteriormente, pudieran hacer uso de la palabra en los tribunales.

Así, aunque la mayoría de los litigantes sabía atacar y defenderse con eficacia y con precision instintivas, pronto se advirtió la 
necesidad de un manual que ofreciera de forma clara y sistematizada, unas técnicas sencillas de argumentación y unos métodos prácticos de debate. Es, por lo tanto en este contexto, en donde la Retórica comienza a justificarse por la necesidad de su empleo y por su funcionalidad (Gómez 419).

Años más tarde, Gorgias de Leontinos, llevará la retórica a Atenas y con este acto se considera que fundó la tarea de la abogacía (Gómez, 2007). Aristóteles (1976) continúa la sistematización de la retórica y describe que su ejercicio persuasivo lo hace a través de la razón, del sentimiento y de la convicción: el logos, el pathos y el ethos. Para cada una de estas formas persuasivas existían las técnicas correspondientes, todas organizadas alrededor del discurso.

Posteriormente otras prácticas sociales y disciplinas del conocimiento, como la política, empezaron a usar la retórica, pero, primordialmente, la retórica se mantuvo durante siglos como una técnica lingüística que formaba parte del lenguaje profesional del abogado. Se puede apreciar lo anterior con los "tópicos" que hoy en día hay quienes los ubican en el campo de la filosofía, pero los "tópicos", es una forma de conocimiento profesional del abogado tal y como se puede leer en los escritos de Cicerón (Trad. 1997). Cuando se estudia la historia de la retórica y se encuentra que en sus inicios fue un lenguaje especializado para el litigio, encuentra fundamento esta reinterpretación de la retórica como vía para fortalecer la profesión del abogado.

Sin embargo, la argumentación y la dialéctica puesta en práctica con la retórica fue vista como un enemigo por quienes se imponen por la fuerza (Adrián, 2008). Cuando la retórica fue atacada lo que se hizo fue disolver el acto retórico. La retórica fue convertida en ornato despojándola del logos, de la razón y dejando solo la vestimenta estética que tiene su mayor expresión en el acto escenográfico de la declamación. Así que la imagen actual popularizada de la retórica es una tergiversación que sigue conviniendo al status quo. Platón inició el embate contra la Retórica, señalando a sus practicantes como sofistas, aunque este mismo término fue deformado pues en su origen significaba sabio (Ramírez, 2013). La retórica continuó durante la Roma Clásica para menguar su presencia en el medioevo, resurgir con el Humanismo italiano y sucumbir, deformada, por el embate de la Iglesia y de la mano de Petrus Ramus. La retórica, durante los tiempos que pudo mantenerse viva, preparó para usar la palabra en público y generó un poderoso sistema pedagógico para desarrollar habilidades de expresión verbal incluyendo las habilidades de escucha, los gestos, y movimientos corporales (Reyes, 1955). La retórica, como cúspide de esta formación, fue parte del lenguaje profesional del abogado. Ahí tenía una de sus fuentes nutricias. A continuación, abordaremos el concepto de lenguaje profesional para fortalecer la propuesta de la importancia de la retórica en la formación del abogado.

\subsection{El lenguaje profesional}

Las prácticas sociales a las que denominamos como profesión se definen, entre otros rasgos, por la posesión de un lenguaje esotérico que adquieren los practicantes a lo largo de su formación inicial y ejercicio profesional (Hortal, 2002). Este lenguaje profesional, esotérico para el lego, habilita para el uso de los conocimientos, habilidades y actitudes que conforman la práctica profesional.

Por el uso práctico de este lenguaje es claramente distinguible un profesionista, no solo respecto a profesionistas de otras disciplinas, sino también respecto a un técnico: el profesionista, con el uso de ese lenguaje, realiza su profesión y como parte de ella "explica " al usuario, así mismo y a otros profesionistas su actuar. El técnico, por su parte, podrá intervenir y quizás solucionar algún problema, pero puede ser que la explicación de su acción sea mínima o ausente. Además, en niveles complejos de la actividad profesional, el uso del lenguaje profesional no solo es un rasgo característico, sino la base misma de la efectividad e innovación. El comportamiento efectivo y variado, como puede definirse el acto inteligente, funcional y competencial (Ribes, 2018) tiene su fundamento en ese dominio del lenguaje profesional.

Los "lenguajes profesionales", como prácticas culturales, tienen historia y son permeables a otros lenguajes: surgen en momentos y lugares determinados. Así mismo, se interconectan con los lenguajes de otras profesiones: se influyen, determinan, subordinan e innovan. Esta influencia también se da con otros lenguajes como el de la vida cotidiana. En estos tiempos, el lenguaje de las ciencias de la computación es un caso claro de un lenguaje profesional al que la vida cotidiana y otras profesiones se subordinan. Todos recordamos la expresión de "cambiarse de chip "cuando se le pide a una persona que cambie su comportamiento acerca de algo. 
El lenguaje de una profesión tiene una historia, va incorporando en su léxico nombres, técnicas, habilidades que forman la profesión. Algunas veces el origen de este léxico se pierde como el caso de la "cátedra" que no es otra cosa sino un desnivel apropiado para ver al grupo al impartir clase, un objeto en sí, y que ahora es parte del lenguaje profesional del docente universitario y ya no como referente a un objeto sino a la impartición de clases a nivel universitario y con gran dominio por parte del que da la clase. De tal manera que, si se plantea la historia de una profesión, eso implica hacer la reconstrucción del origen y transformaciones que ha experimentado su lenguaje profesional. Esta revisión histórica permite ver cuáles han sido los énfasis, las preocupaciones del gremio en cuestión, los problemas que surgen en el ejercicio y cómo se han solucionado. El lenguaje es un condensado de conocimientos (Vygotsky, 1978; Wittgenstein, 1953), por lo tanto, el lenguaje profesional incluye el saber del gremio para mejor actuar su profesión.

Decíamos que algunos lenguajes profesionales llegan a ser tan importantes que pueden llegar a definir a otros lenguajes. Esa influencia también se puede rastrear históricamente, haremos esa tarea para el caso del lenguaje profesional del abogado.

La retórica, como ya propusimos, surgió como un lenguaje especializado para resolver disputas entre hombres libres. Es a lo que Wittgenstein (1953) denomina un "juego de lenguaje": un entrecruzamiento entre lenguaje, pensamiento y actividad. Diversas disciplinas se han apropiado de la retórica y la han silenciado. Han hecho olvidar ese origen práctico y profesional de la retórica. Ahora bien, considerando lo anterior, podemos explicar de esta manera la relación entre retórica y la profesión de abogado: en primer la retórica clásica y la profesión de abogado no son dos componentes distantes. Por el contrario, al romper este binomio, el resultado es tener abogados que no saben persuadir al juez y, por tanto, son malos en su desempeño profesional en el litigio.

Cuando la retórica se olvidó de la abogacía fue pulverizada al atribuírsele lisonjería e inutilidad. Cuando la abogacía se olvidó de la retórica se volvió una tarea burocrática. Un simple ejercicio técnico repetitivo e inefectivo.

Por el contrario, si mantenemos la identidad entre retórica y abogacía podemos retomar el brillo en la oratoria dentro del ejercicio del derecho en América Latina. Regresará la ética y la dignidad a los recintos de la ley. Si la abogacía vuelve a la retórica mucho del conocimiento clásico de esta disciplina revivirá.

A la luz de estas consideraciones concluimos que la retórica es, primero que nada, un lenguaje profesional: el lenguaje de los abogados. La retórica surgió junto con la práctica jurídica, esto se olvida a veces cuando se forma abogados de manera inicial en la universidad o cuando se les imparte formación continua cuando ya están en el desempeño profesional y ya no debe suceder más este olvido. De la misma manera, la formalización de la retórica marcó la aparición del abogado.

\subsection{La retórica en la preparación del abogado mexicano moderno}

La propuesta de recuperar la retórica en la tarea judicial surgió auspiciada por las condiciones culturales y laborales generadas en el proceso de autoformación del juez familiar en el Distrito Federal que se sigue para implementar los juicios orales (Muñozcano y Farfán, 2016).

Desde el año 2012, el Tribunal Superior de Justicia de la Ciudad de México (TSJCDMX) implementó la justicia oral familiar. Se siguió un proceso intencionado, planeado, evaluado y fundado en un trabajo interdisciplinar en el que los jueces se autoformaron bajo la asesoría y concurso de especialistas de diferentes disciplinas como la sociología, la psicología, la pedagogía y la filología.

En la preparación de los jueces familiares que transitaban de juzgados "tradicionales" a "juzgados orales”, se planteó estudiar argumentación. En el 2016, después de que el TSJCDMX trabajó con especialistas del Instituto de Investigaciones Filológicas, se decidió seguir la ruta de la retórica y no la de la argumentación. Para esto se elaboró una propuesta formativa con dos influencias, la psicología interconductual y la retórica clásica. De la psicología interconductual se retomó el modelo de discurso didáctico (Ibañez, 2011), así como su taxonomía del aprendizaje que se rige por el criterio del desligamiento funcional (Ribes, 1990). Esta recuperación de la psicología permitió ordenar el programa de aprendizaje de la retórica y su enseñanza. De la retórica clásica se siguió el modelo pedagógico para la enseñanza de la retórica propuesto por Quintiliano (Trad. 2000) y Cicerón (Trad. 1997), fundamentalmente se recuperó el 
proceso didáctico que inicia con la presentación del modelo de retórica, la imitación de este modelo por el alumno y culmina con la recreación del modelo aplicándolo a otros casos. La pedagogía retórica clásica puede ser revisada a profundidad en el libro de Retórica Antigua de Alfonso Reyes (1955).

Esta formación del juez en retórica se elaboró gracias a los auspicios del instituto de Investigaciones Filológicas de la UNAM a través del doctor Ramírez Vidal, del doctor Eduardo Fernández y del doctor Juan Lorenzo de la Universidad Complutense de Madrid quienes impartieron un curso de retórica jurídica el cual duró tres meses. En esta primera fase de trabajo, un grupo de 40 jueces, magistrados y proyectistas de sala tomaron clases con diversos especialistas en retórica. De este nuevo e intenso intercambio, el auditorio planteó insistentemente a los ponentes la necesidad de preguntarse sobre la retórica desde el punto de vista del impartidor de justicia. Fue así que surgió la propuesta de concebir una "retórica jurisdiccional", la cual se refiere a la retórica del juzgador. Los especialistas tomaron cuenta de esa propuesta y tomaron conciencia que la retórica que se ha estudiado pone el énfasis en la retórica del litigante y que era sumamente relevante esta "retórica jurisdiccional". La culminación de esta primera etapa fue la realización del Primero Congreso de Retórica Jurídica. En el año 2019, a fines del mes de marzo, se realizará el Tercero de estos eventos.

Después de esta primera fase de trabajó los jueces familiares se prepararon pedagógicamente para formar en la retórica al grueso del personal de los juzgados, así como a los distintos funcionarios que también participan, como el defensor de oficio, el ministerio público, entre otros.

Cuando se empezó a trabajar, en la segunda parte, con la formación pedagógica para que los jueces se prepararan para impartir un curso, se añadió el concepto de acto retórico. Con este concepto se dio un giro radical al trabajo formativo pedagógico: el acto retórico se convirtió en el contenido central de la formación del juez.

El acto retórico incluye, en el logos, la argumentación. Pero va más allá al incluir el ethos y el pathos (Ramírez, 2017). El ethos corresponde a lo que ahora referimos como "el porte ", la personalidad del juzgador, mientras que el "pathos " refiere a la emoción que genera en su audiencia.
El otro concepto clave para la formación es la retórica jurisdiccional, la cual permite vincular el acto retórico y el juicio oral desde la participación del juez. Este trabajo con el acto retórico y la retórica jurisdiccional adquiere sentido particular para la práctica tanto del impartidor de justicia como del litigante destacando que la perspectiva desde la que se hace es la profesión, el ejercicio del derecho. Si bien la filosofía, la lingüística, la lógica y la propia retórica, como disciplinas, alimentan este análisis, el sentido y objeto de realizarlo es la práctica profesional: la abogacía.

Así fue el proceso creativo colectivo que llevó a poner el centro a la retórica jurisdiccional como parte de la autoformación del juez. Es decir, el lenguaje, el lenguaje profesional se convirtió en la clave para el cambio en la práctica del profesional del abogado.

\section{CONCLUSIONES}

Como resultado de este artículo, advertimos que el núcleo de las virtudes en donde se asienta la retórica, es su origen como un lenguaje especializado para resolver disputas entre hombres libres. El ejercicio del Derecho se apropió de ese propósito. Es por tal razón que concluimos que la retórica es, primero que nada, un lenguaje profesional: el lenguaje de los abogados. Es ahí donde se institucionaliza ese uso del lenguaje propicio para el encuentro y la resolución de los conflictos.

De lo anterior se desprende otra conclusión, en el sentido de advertir cómo se da ahora esta construcción de la profesión de abogado alrededor del uso de la retórica. En la visión de profesión desde la pragmática del lenguaje, se coincide con Hortal (2002), en el entendido de que al poseer un "lenguaje esotérico" y "una larga preparación previa para ejercerla" se forma el abogado. De manera que aprender el lenguaje de la retórica significa apropiarse de la cultura que identifica a los abogados.

Sin embargo, la relación entre retórica y abogacía no es un círculo cerrado, por el contrario, los beneficios de la retórica no son para una práctica profesional aislada, como se podría equivocadamente suponer puesto que la retórica está estrechamente relacionada con la vida social. Por lo tanto, otra conclusión a la que llegamos es que la cultura jurídica actual 
en México y otros países latinoamericanos, da la ocasión para la propuesta aquí planteada de recuperar la retórica para transitar de los juicios "tradicionales" a los "juicios orales". Existe ya un antecedente de dicha propuesta en México, la cual comentamos en el cuerpo del trabajo y que por los buenos resultados arrojados alienta a seguir con esa experiencia pedagógica. Como fruto de la experiencia referida y en consonancia con los argumentos desarrollados en este artículo, otra conclusión fundamental a la que llegamos es la de recomendar, para la formación jurídica, el modelo pedagógico para la enseñanza de la retórica propuesto por Quintiliano (Trad. 2010) y Cicerón (Trad. 1997), que inicia con la presentación del modelo de retórica, seguido de la imitación por parte del alumno y culmina con la transferencia del modelo aplicándolo a otros casos. Encontramos que este modelo didáctico se puede actualizar para la didáctica de la abogacía del Siglo XXI, en una propuesta formativa sostenida en la psicología interconductual (Ribes, 1990), retomando el modelo de discurso didáctico, así como su taxonomía del aprendizaje. Esta es una veta que hay que seguir trabajando. La veta en la cual la profesión de abogado, la retórica y la enseñanza se entrelazan.

Sabemos lo polémico que pudo haber sonado el insistente uso de la retórica para formar abogados, confiamos que al terminar de leer este artículo esa desconfianza y animadversión se reduzca o, aún mejor, desaparezca. Resulta paradójico que en las escuelas de Derecho se siga admirando y estudiando el Derecho Romano y se desprecie u omita el mecanismo pedagógico a través del cual se aprendió durante la Antigüedad. Esta es una tarea de recuperación del conocimiento clásico, pero también es una tarea de innovación pedagógica para actualizar y dar nueva vida a los saberes antiguos con los que se constituyó la profesión de abogado. 


\section{BIBLIOGRAFÍA}

- Adrián, L. (2008). Petrus Ramus y el ocaso de la retórica cívica. Revista internacional de Filosofía Latinoamericana, 13 (43), 11-31. Recuperado de: http:// produccioncientificaluz.org/index.php/ utopia/issue/view/337,

- Aristóteles. ( 1976). Retórica. España: Gredos.

- Cáceres, E. (2016). Pasos hacia una revolución en la enseñanza del derecho en el sistema romano-germánico. México: UNAM-IIJ,

- Cicerón. (1997.) De la invención retórica. España: Gredos.

- Farfán, E. y Molina, M. (2016). El error del simulacro. Pasos hacia una revolución en la enseñanza del derecho en el sistema romanogermánico. Coordinador Enrique Cáceres. México: UNAM.

- Gómez, M. (2007). El zigzagueante y dilatado recorrido de la retórica: un acercamiento a su cambiante valoración. Revista Interlingüistica, (17), 410-428.

- Hortal, A. (2002). Ética general de las profesiones. España: Desclee de Brouwer.

- Ibáñez, C. (2011). La noción de discurso didáctico en el análisis psicológico de los procesos educativos. Acta Comportamentalia: Revista Latina de Análisis de Comportamiento, 19 (1), 125-134.

- Jiménez, R. (2013). ¿Se puede enseñar a persuadir a los alumnos de derecho con el metadiscurso? Una propuesta docente". Revista de Llengua i Dret, (59) 42-58.

- Muñozcano, A.y Farfán, E. (2016). El cambio en la práctica jurídica familiar a través de la pedagogía. reporte de una experiencia de éxito en México. Revista Pedagogía y Didáctica Del Derecho, 3 (1), 106-126.

- Muñozcano, A. y Rivera, E. (2017). En la Brega. El camino hacia la oralidad familiar. México: TSJCDMX,.

- Palma, E. y Elgueta, M. (2018.) Aprendizaje y Didáctica del Derecho. México: Tirant lo Blanch,
- Ortega, A. (2000). Quintiliano Institutio oratoria: Sobre la formación del orador. Salamanca: Universidad Pontificia de Salamanca. Recuperado de: http:// biblioteca.org.ar/libros/154922.pdf.

- Ramírez, G. (2008). El Sofista y el filósofo en Platón. Revista De Filosofia De La Universidad De Costa Rica (46), 116-117. Recuperado de: https://revistas. ucrac.cr/index.php/filosofia/article/view/7392, fecha de consulta el 6 de febrero de 2019

- Ramírez, G. (2017). La Pistes fides como el objeto propio de la retórica. Quadripartita ratio. Revista de Retórica y Argumentación, 3 (5), 37-48. Recuperado de: http://www.iifilologicas.unam.mx/uploads/rir-1/rir1.pdf, fecha de consulta el 15 de enero de 2019

- Reyes, A. (1955.) Retórica. Obras completas. México: Fondo de cultura económica, tomo XIII.

- Ribes, E. (1990). Psicología General. México: Trillas, Primera edición.

- Ribes, E. (2018). Una introducción a la psicología. México: Manual Moderno.

- Ríos, E. (2013). La oralidad en los procesos civiles en AméricaLatinaReflexionesapartirdeunaobservación práctica. Recuperado de: http://biblioteca. cejamericas.org/bitstream/handle/2015/1167/ laoralidadenlosprocesosciviles_erios. pdf?sequence $=1 \&$ isAllowed $=y$

- Rivera, A. (2019). Crisis de régimen, autoritarismo subnacional y reforma penal en México. Revista Perfiles Latinoamericanos, 53 (27),1-25.

- Schon, D. (1998). El profesional reflexivo. España: Paidós.

- Varela, J. (1998). Teoría de la conducta: extensiones sobre el desarrollo del comportamiento inteligente. Acta Comportamentalia: Revista Latina de Análisis del Comportamiento, 6 (3), 87-97.

- Vygotsky, L. (1978). El desarrollo de los procesos psicológicos superiores. México: Grijalbo.

- Wittgenstein, L. (1953). Investigaciones filosóficas. España: Gredos. 